\title{
Approaches to university education integration into innovative ecosystem
}

\author{
Stanislav Amelin ${ }^{1}$, Elena Enina ${ }^{1}$ and Yulia Pahomova ${ }^{1, *}$ \\ ${ }^{1}$ Voronezh State Technical University, 14, Moscow Av., Voronezh, 394026, Russia
}

\begin{abstract}
Professional realization and education items - are most important in our life. And this is no wonder by considering how much time each of us spends on study and on work and how much depends on it. And of course, radical changes which are taking place at the present time have no choice but affect these spheres. Today in Russia there is a lot of attention paid on discussion of innovations, digital economics, labor efficiency and competitive ability. However these plans are unrealizable without systematic approach to human capital development including attraction and retention of best minds as well as ensuring conditions for growth of progressive companies-recruiters. One of the most important tasks of these companies is on creation of new high-quality working places, inherent for technological, diversified, creative economics economics of knowledge. By human capital production it becomes principal the focus on "soft" skills: on width of view, ability to hold discussion, to present results in various ways, to communicate, to work in teams. And then the question arises not only what we teach, but also how and where we teach. There are considered in the article items of educational process in university, what must university do, in order to get rid of the imitation in research activity, how to solve the problem of interdisziplinarity in university; how to form the organizational cultures and activity norm in university.
\end{abstract}

\section{Introduction}

Researchers of transnational consulting company Boston Consulting Group (Russia 2025: From personnel to talents, 2017) have made conclusion that more than $80 \%$ of employable population of Russia do not have skills and competences for working in modern markets and in the country itself there is no demand for knowledge. There are engaged in high-quality labor, relating to category "knowledge" (intellectual work, creative and non-routine tasks), only $17 \%$ of population. This is less than 1,5 times, than in Japan and USA, 1,7 times less than in Germany; twice lower than the index of Singapore and 2,6 times - than in Great Britain. System of Russian high-school education clearly does not cope with the task: recipe of diploma is transformed into empty social ritual, purpose of which is - pass in the society or army respite; education does not promote career, does not made the basis of social success, education is replaced by graduation, and professionalism

\footnotetext{
*Corresponding author: Yulia198007@mail.ru
} 
with - skill of arrange and adaptivity. As the result $91 \%$ of Russian recruiters consider that graduates do not have practical skills, and $83 \%$ conceive the level of preparation in higher education institution as medium or low [1].

\section{Materials and methods}

Speaking about educational programs realization models we must not forget that any high education institution is - an established system, which is rather difficult for rapidly rebuilding. That is why absolutely, any changes must base on the formed experience, traditions of high education institution as well as conditions where this high education institution is functioning today (region, branch, political and economic situation) (Tolstykh, Shkarupeta, Kostuhin \& Zhaglovskaya, 2018), (Kolesnikova, 2017), (Kameron \& Kuinn, 2001). And in this system determining link must become consumer. For high education institution consumers are applicants, their parents, enterprises of branch. They are those who "orders" the criteria of quality of education, target figures. Any "modes" are - tools for realization of this goals, and not the goal itself. Skill of head is - to choose that tool which is the most suitable for certain task under certain conditions [2].

Nuclear program limits the choice possibility for student. This greatly facilitates the work of teacher, although increase his liability from the position of base for following courses. From the other side, the nuclear program unifies all students, regardless of their potential. As proposal for solving the problems of Russian baccalaureate may serve a model, integrating proposed formats. For example, nuclear program is - multidisziplinary program including in it whole range of basic general scientific courses as well as art courses, history and others, necessary for formation of identity with wide outlook and system thinking. Another realization format of the same program but in other course may become focus on interactive classes in small groups and free choice of $1 / 3$ courses. Free choice of major-a (profile) after second course and so on [3].

The restructuring of educational program after the integrated format requires the solving of two primary fundamental problems: firstly, to provide to high education institution with teachers who are ready for corresponding with free education format; second, to link with format with standards and rules, within frameworks of which university is forced to function. Such approach is realized for example in Tyumen state university in the School of advanced studies.

Another interesting practice, realized in Russian high education institutions is education after the model of seven Artes Liberalis (Artes Liberales) (courses electivity, individualization of education process, education targeted on needs of student and so on). This model is carried out to different extents by Saint-Petersburg State University and by Russian Presidential Academy of National Economy and Public Administration by the President of RF.

One of the most seriously problem faced by both high education institutions is freedom of choice of courses by students. Variant, where one and the same discipline may be chosen by students of different courses is not simple task, but such electiveness is the basis of individual approach to modern study of student. Obviously, from the point of view of sequence of disciplines study it is not important that student has chosen at first: history of music or history of literature. He chooses that, what is important for him, interesting for him or by other reasons, but this is his choice. Variability of courses, possibility for student by himself - in reality and not fictitious, - to build his own education pathway is cornerstone of idea liberal arts education [4].

We are living in another world, world of digital economics, which submits requests to competences and knowledge of graduates. Speed of market change, rapidly changing political and economic situation in the world, new digital technologies development 
tendencies, practically in all branches, require the qualitative other competences and other approaches as in business and in education. New approaches must be significant distinguish from traditional approaches, orientated on gradual technologies development, on longitude temporary phased implementation. Time and quality become main criteria for making decision about investing in this or that business-project. Under these conditions the key moment of efficiency and competitive ability of innovative projects is professionalism of their participants, level of their liability, innovativeness, creativity, thinking system, flexibility and adaptability, focus on result. All these competences must be formed already at the level of study, in the high education institution what requires the principle other approaches to educational models of development and knowledge crunching [5].

\section{Results}

For each high education institution there is acute problem of educational model development, adjacent with regional economic specificity, social sphere, science, business environment. Practical implementation of such adaptive model through different educational formats is also represented as task of no less importance. With all variety of potential educational models as unified requirements is their permanent focus on qualitative an innovative aspects, which are adequate for processes, which are carrying out in business, industrial and other spheres of national economic. That is why I consider that as passthrough approach by implementation of any baccalaureate formats must be project approach [6].

In normative documents determining the development of education system in Russia, it is declared the strengthening of the activity and project component of education in complex with competence approach. Among the most important competences for all degrees of continuously education there are determined research competences. Their formation is accompanied by the increase of share and role of self-work of pupils and students. Parallel to this in scientific - education sphere there is submitted a claim for increasing of publication activity of researchers, as well as teachers, seeking the highest qualification category. This supposes the presence of ability and skills to finalize the results of project and research activity in texts of designated (academic) format. However the real practice of requirements realization designated be education standards of new generation often comes into conflict with sett task of development of valuable, personally origin of education. One of the forms of showing of such conflict is the imitation of education and scientific activity.

Imitation of research activity is - not term of single meaning. If as the imitation to consider the borrowing of ideas, innovations, than this thesis is disputable. History of countries which were the same development level as Russia, and which achieved success shows that for them the priority was not generating of innovations but an imitation, i. e. borrowings of technologies, innovations, routines by western countries. Japanese have nothing created but only imitated very intensively bought technologies, renewed production apparatus. As the result of what they entered the sufficient high level and then began to generated innovations. Such situation is characterized for China and for India. In order the reasonable borrowing it is necessary to have experienced specialists, high level of human capital and fundamental science, understanding of the fact what it is occurring in the world and what is prospectively, the ability to perceive new, understanding of what must be borrowed. Scientific activity after its essence is at its core consists in the fact, that to find the balance between that what is already known and relative new in this field for this problem [7]. Axioms, theories, postulates, methodologies - any research begins from already known truths. The most difficult in science is - the skills of scientists to balance between the confirmation of that what is already known and finding out new. Main goal of high education institution, forming the knowledge economics consists in generation and 
transferring the fundamental knowledges, based on which there are building the long-term strategies of development of high education institution economics, branches, territories, country in whole. Importance of innovations for economics and competitive ability of country technological structures of N. Kondratiev well demonstrate [8].

But if under the term of imitation of research activity to consider the replacement of real work to "for show", where research chops have priority meaning in comparison to real researches this is undoubted negative process. How to deal with it? The solution of this problem has systemic character. At institutional level the assessment of high education institutions is built at determined set of degree-credit enrollment, thesis defense plans and other digital criteria. And efficiency of high education institutions is directly connected with its financing. From the other side, the introduction of efficiency contracts also is built on certain digital indexes, what stimulates teachers to ensuring in any ways these indexes, on which directly depend their financial wellbeing [9].

As for students, students in the master's program, then the solving of problem is also in the field of motivation: there must be interesting here and now, but also give certain bonuses for future. Formation of institutions of commercialization of scientific activity in high education institution, allow forming flexible alliance with business, invest innovations, stimulate the creativeness of young inventors, find a compromises in implementations of interests of different vectors of participants, ensuing speed of project implementation from idea generation till product launch can solve the problems of motivation of research activity as for students as well as for their tutors [10].

Describing the interdisciplinarity problems, firstly we wanted to speak about the meaning of interdisciplinary institutes. Interdisciplinary researches are implemented relatively long ago. And earlier there are existed and biochemistry and in many contact fields of knowledge there were carried out interdisciplinary researches, but just now it is arising the question, why their specific gravity and the necessity in them so significantly increased. The growth of modern massive of interdisciplinary researches most probably is connected with that that for objects of knowledge of modern science becomes difficult selfdevelopment systems with it them included human.

Interdisciplinarity is - not the goal itself, but a method of organization of scientific researches for solving of difficult (complex) problems (Tolstykh, Vertakova, Shkarupeta, Shishkin \& Krivyakin, 2017). There are arising tasks which have complex multi-focused object, and everything is depends and on this object and on set task. Imposing to high education institute some schemes and structures, artificial combining, which are not arose out of goals not tasks, as it seems to me, will only create new bureaucratic structures [11].

That is why it is worthy to speak about the format of institute only from the position of implemented goals and tasks. Effective formats of interdisciplinarity, are as it seems to me, temporary dynamic structures, organizing for example under grants and project competitions.

Innovative university management is based on transformation to the side of professional profit oriented business. Professional because in universities there are as the main thing is the qualification of its employees. Profit oriented business because the focus by management is located to the side of accessing into market relations by itself. Such transformation requires synthesis of all kinds of knowledge, competences, scientific directions. Institute's interdisciplinary project within frameworks of profit oriented university includes the active component of financing of internal environment in accordance with the needs of its development. In this concept it is focused on the fact, what innovative thing university must take in order to respond the external challenges and to ensure development (Russell \& Smorodinskaya, 2018).

In high education institution of such format there must appear subdivisions which from one side are professional offices, ensuring the transferring the knowledge, contacting with 
industry, intellectual property protection, qualification increasing, searching of financial tools based on interaction with different funds, work with graduates, and from the other side are interdisciplinary project-oriented research and scientific centers, which are arising by faculties and academic department as the second main way for group and academic work. Such universities are open for radical changes of different university systems, culture, process of admission, content of education, terms and forms of education. Practice evidences about the fact, that the adopting by university the management, characterizing for business has made the university management more effective and corresponding for open economics.

\section{Discussions}

World experience shows that, most successful enterprises-universities became those who combining in themselves three elements:

- The ability of use of possibilities, provided by external environment related to earning money;

- Oriented on development organizational structure;

- Experienced management team and academic culture.

But it is necessary to understand that by high education institution based on principles of interdesciplinarity there are possible negative moments [12]:

- Leaders move away from those whom they lead;

- Internal unity of university workers is weakened;

- Social ethics is directed not on solving of social-economics problems but on profit;

- Has low ability for education innovations;

- Enterprise-university works often by ignoring the academic culture.

One of formats based on the principle of interdisciplinarity may be proposed the creation of the center of project researching or project office as unified informational organizational, technological space of innovative activity. The task of such center must become: the generation of ideas, access organization to technological and to potential of best centers of competences in certain branches, formation of resources ensuring of innovative process (analytical, forecasting, infrastructural, investment-financial), formation of personnel potential for high-technological business and productions (Karapetyants, Kostuhin, Tolstykh, Shkarupeta \& Krasnikova, 2017).

\section{Conclusion}

At the present time Russia has not achieved success in competition for taking a place in economics of knowledge. Share of high-technological production is low, not more than $17 \%$ of working places of country may be fitted to the category "Knowledge", in scarce supply are also universal competences. Such situation is caused with three key reasons:

- There are no critical mass of demand for knowledge;

- The education system does not prepare the personnel for economics of knowledge;

- There is no created the environment necessary for development and self-realization of human.

We see as countries-leaders transform actively their education systems, focusing on development of cognitive knowledge instead of general "loading" of knowledge. They take active part at retraining of national labor resources and help them to adapt to changed working environment, attracting best specialists into education sphere and maximal use the possibilities of digitization. 


\section{References}

1. A.A. Auzan, World economics and international relations 61-10, 96-105 (2017)

2. T. Tolstykh, E. Shkarupeta, Y. Kostuhin, A. Zhaglovskaya, Proceedings of the 31th International Business Information Management Association Conference (IBIMA) (Milan, 2018)

3. K.S. Kameron, R.E. Kuinn, Diagnostic and change of organizational culture (St. Pete, Saint-Petersburg, 2001)

4. D.P. Kotter, In Advance of changes (CJSC OLIMP-BUSINESS, Moscow, 2003)

5. I. Karapetyants, Y. Kostuhin, T. Tolstykh, E. Shkarupeta, A. Krasnikova, Proceedings of the 30th International Business Information Management Association Conference (IBIMA) (Madrid, 2017)

6. I. Karapetyants, Y. Kostuhin, T. Tolstykh, E. Shkarupeta, E. Syshsikova, Proceedings of the 30th International Business Information Management Association Conference (IBIMA) (Madrid, 2017)

7. J. Luo, Technological Forecasting and Social Change (2017) ISSN 0040-1625, https://doi.org/10.1016/j.techfore.2017.06.033

8. M.G. Russell, N.V. Smorodinskaya, Technological Forecasting and Social Change (2018) ISSN 0040-1625, https://doi.org/10.1016/j.techfore.2017.11.024

9. S. Vasin, L. Gamidullaeva, E. Shkarupeta, A. Finogeev, I. Palatkin, European Research Studies Journal XXI-3, 63-76 (2018)

10. T. Tolstykh, E. Shkarupeta, Y. Kostuhin, A. Zhaglovskaya, Proceedings of the 31th International Business Information Management Association Conference (IBIMA), 4738-4746 (Milan, 2018)

11. T. Tolstykh, Y. Vertakova, E. Shkarupeta, I. Shishkin, K. Krivyakin, Proceedings of the 29th International Business Information Management Association Conference (IBIMA), 2180 - 2191 (Vienna, 2017)

12. T. Tolstykh, E. Shkarupeta, I. Shishkin, O. Dudareva, N. Golub, Advances in Intelligent Systems and Computing 622, 736-743 (2018) DOI: 10.1007/978-3-31975383-6 